\title{
Commentary: Clinical Approach to the Differential Diagnosis between Behavioral Variant Frontotemporal Dementia and Primary Psychiatric Disorders
}

\author{
Manish Kumar Jha* and Elena Ivleva \\ Department of Psychiatry, University of Texas Southwestern Medical Center, Dallas, TX, USA
}

Keywords: frontotemporal dementia, forensic psychiatry, psychosis, aggression, measurement-based care

\section{A commentary on}

OPEN ACCESS

Edited by:

Adriana Mihai,

University of Medicine and Pharmacy of Târgu Mureş, Romania

Reviewed by:

Liana Dehelean,

Victor Babeş University of Medicine and Pharmacy Timişoara, Romania Costin Roventa,

Prof. Dr. Alexandru Obregia Clinical Hospital of Psychiatry, Romania

${ }^{*}$ Correspondence:

Manish Kumar Jha manishjha2201@yahoo.com

Specialty section:

This article was submitted to

Public Mental Health,

a section of the journal

Frontiers in Psychiatry

Received: 18 December 2015 Accepted: 09 February 2016

Published: 24 February 2016

Citation:

Jha MK and Ivleva E (2016) Commentary: Clinical Approach to the Differential Diagnosis between Behavioral Variant Frontotemporal Dementia and Primary Psychiatric

Disorders.

Front. Psychiatry 7:23,

doi: 10.3389/fpsyt.2016.00023
Clinical Approach to the Differential Diagnosis between Behavioral Variant Frontotemporal Dementia and Primary Psychiatric Disorders

by Ducharme S, Price BH, Larvie M, Dougherty DD, Dickerson BC. Am J Psychiatry (2015) 172(9):827-37. doi:10.1176/appi.ajp.2015.14101248

We welcome the recently published review by Ducharme and colleagues (1) and wish to highlight matters pertinent to aggressive behavior in their report. Aggression in psychiatric hospitals has gained widespread public attention (2). Mentally ill treatment-refractory patients who display aggressive behavior are either transferred to maximum-security forensic state hospitals (3) or sent to correctional facilities, which often struggle to keep up with the epidemic of mental illness and shortage of psychiatrists (4). Fourteen percent of patients with behavioral variant frontotemporal dementia (bvFTD) present initially to psychiatric care due to criminal behaviors (5). This highlights the importance of considering bvFTD as one of the key differential diagnosis in treatment-refractory forensic patients with progressively worsening cognitive functioning and high rates of violence as well as in patients with new-onset criminal behavior. Emerging biomarker-based reports indicate substantial overlap in cognitive dysfunction and underlying anatomical and functional brain abnormalities, such as frontotemporal gray matter loss, spanning psychotic disorders (6), and dementias (1). These findings call for novel dimensional approaches to psychiatric diagnoses and treatment such as those emphasized by the Research Domain Criteria (RDoC) initiative (7).

We have reported on our successful management of such a case from a maximum-security hospital, who presented with long history of psychosis refractory to multiple treatment interventions including clozapine and electroconvulsive therapy (8). Our treatment decisions were driven by revision of diagnosis from schizoaffective disorder to FTD, based on cognition (Repeatable Battery for the Assessment of Neuropsychological Status and Montreal Cognitive Assessment) and neuroimaging (structural magnetic resonance imaging) workup, as well as by utilizing measurement-based care (MBC) (9). The principles of MBC include routine measurements of symptoms, side effect, and tolerability along with modification of treatment regime based on these measurements, while best defined for treatment of major depression can be extended to management of other chronic mental illnesses (9). We used data collected as part of state-law mandated monitoring of restraint(s) and/or seclusion(s) (10) to serve as measurements, which guided our decision to change medications or their dose. For example, during the course of treatment and as reported previously (8), we re-evaluated the utility of medroxyprogesterone by reducing its dose and frequency, which was 
associated with sharp increase in aggression. Utilizing principles of $\mathrm{MBC}$, we re-instated the dose of medroxyprogesterone and added sertraline, which in turn resulted in even greater reduction in aggression. As impulsivity and disinhibition are hypothesized to underlie the aggression in bvFTD patients, $37.4 \%$ of whom exhibit criminal behaviors (5), we implemented structured behavioral and environmental modification programs. These interventions led to considerable improvement in the patient's psychosis, social behaviors, impulsivity, aggression, and insight, despite persistent cognitive symptoms.

This systematic review by Ducharme and colleagues is a valuable addition to literature offering a clear, step-wise differential diagnosis algorithm directly applicable to various clinical settings. However, lack of access to neuroimaging and expert

\section{REFERENCES}

1. Ducharme S, Price BH, Larvie M, Dougherty DD, Dickerson BC. Clinical approach to the differential diagnosis between behavioral variant frontotemporal dementia and primary psychiatric disorders. Am J Psychiatry (2015) 172(9):827-37. doi:10.1176/appi.ajp.2015.14101248

2. Seager S. Where Hell Is Other Patients. Page A31 of the New York Edition; November 11, 2014. The New York Times (2014). Available from: http://www. nytimes.com/2014/11/11/opinion/where-hell-is-other-patients.html?_r=0

3. Texas Administrative Code. Title 25, Part 1, Chapter 415, Subchapter G. Determination of Manifest Dangerousness.

4. Jha MK, Fuehrlein BS, North CS, Brenner AM. Training psychiatry residents at correctional facilities. Acad Psychiatry (2015) 39(1):123-4. doi:10.1007/ s40596-014-0238-0

5. Liljegren M, Naasan G, Temlett J, Perry DC, Rankin KP, Merrilees J, et al. Criminal behavior in frontotemporal dementia and Alzheimer disease. JAMA Neurol (2015) 72(3):295-300. doi:10.1001/jamaneurol.2014.3781

6. Ivleva EI, Bidesi AS, Keshavan MS, Pearlson GD, Meda SA, Dodig D, et al. Gray matter volume as an intermediate phenotype for psychosis: bipolar-schizophrenia network on intermediate phenotypes (B-SNIP). Am J Psychiatry (2013) 170(11):1285-96. doi:10.1176/appi.ajp.2013.13010126

7. Insel T, Cuthbert B, Garvey M, Heinssen R, Pine DS, Quinn K, et al. Research domain criteria (RDoC): toward a new classification framework for research consultation services in state hospitals and correctional facilities may hinder accurate diagnosis of bvFTD leading to under- or over-diagnosis, especially as its prevalence is 10-100 times lower than primary psychiatric disorders. This calls for system-level efforts, such as greater collaboration between academic centers and forensic mental health settings (4), as well as mechanistic research targeting pathophysiology and treatment developments of this devastating neurodegenerative syndrome.

\section{AUTHOR CONTRIBUTIONS}

Both authors (MJ and EI) contributed to the drafting of the manuscript and critical revision of manuscript for important intellectual content.

on mental disorders. Am J Psychiatry (2010) 167(7):748-51. doi:10.1176/appi. ajp.2010.09091379

8. Jha MK, Lambert ES, Beadles BA, Spradling B, Martinez R, Renfro N, et al. A case of frontotemporal dementia presenting with treatment-refractory psychosis and extreme violence: response to combination of clozapine, medroxyprogesterone, and sertraline. J Clin Psychopharmacol (2015) 35(6):732-3. doi:10.1097/JCP.0000000000000414

9. Trivedi MH, Daly EJ. Measurement-based care for refractory depression: a clinical decision support model for clinical research and practice. Drug Alcohol Depend (2007) 88(Suppl 2):S61-71. doi:10.1016/j.drugalcdep.2007.01.007

10. Texas Administrative Code. Title 25, Part 1, Chapter 415, Subchapter F, Rule 415.254 General Requirements for Use of Restraint or Seclusion.

Conflict of Interest Statement: The authors declare that the research was conducted in the absence of any commercial or financial relationships that could be construed as a potential conflict of interest.

Copyright (c) 2016 Jha and Ivleva. This is an open-access article distributed under the terms of the Creative Commons Attribution License (CC BY). The use, distribution or reproduction in other forums is permitted, provided the original author(s) or licensor are credited and that the original publication in this journal is cited, in accordance with accepted academic practice. No use, distribution or reproduction is permitted which does not comply with these terms. 